\title{
Geotextile as a tool against soil erosion in vineyards and orchards
}

\author{
Á. Kertész ${ }^{1}$, A. Tóth ${ }^{1}$, Z. Szalai ${ }^{1}$, G. Jakab ${ }^{1}$, K. Kozma ${ }^{1}$, \\ C. A. Booth ${ }^{2}$, M. A. Fullen ${ }^{2} \&$ K. Davies ${ }^{2}$ \\ ${ }^{I}$ Geographical Research Institute Hungarian Academy of Sciences, \\ Hungary \\ ${ }^{2}$ University of Wolverhampton, $U K$
}

\begin{abstract}
According to practical experiences and laboratory measurements geotextiles may play a significant role in combating soil erosion. Besides the widespread synthetic materials, cheap hand woven geotextiles from organic materials are available as well. They are environment friendly and biologically degradable. The BORASSUS Project funded by FP6 of the European Union (Contract number: INCO-CT-2005-510745) deals with the use of geotextiles made of two kinds of palm leaves (Borassus aethiopum, Mauritia flexuosa), bamboo and jute in ten countries, under different land uses and climatic conditions. Socio-economic benefits of geotextile production in developing countries are also investigated. Within the framework of the project an experimental station was established in North East Hungary (Abaújszántó). 3x4 erosion plots of $10 \times 2 \mathrm{~m}$ were built up to measure soil loss, runoff and soil moisture conditions in order to compare slopes covered and uncovered by geotextiles. Soil moisture conditions are permanently measured on the soil surface and at $20 \mathrm{~cm}$ depth. Three different land use types, i.e. traditional and espalier vineyards and a new orchard plantation are studied under sub-humid temperate climatic conditions. Our first results covering the period of one year show that natural geotextiles decrease soil loss. Runoff volume was increased on plots under geotextile cover. The effect of different land uses influenced first of all the amount of soil loss. No relationship between land use and runoff volume could be detected. Geotextiles favourably affect soil microclimate keeping the soil surface moist for weeks even in very dry periods. The main conclusion is that palm leaf and jute geotextiles are beneficial for the soil by reducing soil and water loss and by regulating soil moisture.
\end{abstract}

Keywords: geotextile, soil erosion, land use, soil moisture. 


\section{Introduction}

Throughout the world valuable natural habitats and huge areas of agricultural use as well as newly constructed embankments (roadsides, levees) are endangered by soil erosion caused or speeded up by human activity, leading to enormous ecological and economical damages. Geotextiles can be a well applicable tool to combat soil erosion in may cases of erosion damage [1-3]. Plastic geotextiles are widespread. In spite of the fact that they can be biodegradable, the production technology and the product itself are expensive and not environment friendly [4].

The BORASSUS project, funded by FP6 of the European Union (contract number: INCO-CT-2005-510745), aims to study the application possibilities of geotextiles made of palm leaves, bamboo and jute, under different climatic conditions and various land use types. Thus the project serves the objectives of sustainable development both by combating soil erosion and promoting the application of environment friendly technologies by using materials of natural origin.

In addition to this, the production of geotextiles made of plants grown in developing countries is beneficial for the poor communities of these countries.

Within the framework of this project, the following research is carried out in Hungary under subhumid temperate climate conditions. Soil loss and runoff are recorded on experimental plots covered and uncovered by geotextiles, soil moisture is permanently registered to study the effect of the geotextiles on soil moisture changes.

The aim of this paper is to present some preliminary results of the above mentioned measurements and to try to explain them from the aspect of the applicability of geotextiles under the given environmental conditions.

\section{Materials and methods}

To carry out research on the effectiveness of geotextiles an experimental station was established in Abaújszántó, NE Hungary (see Figures 1 and 2). Three land use types typical of the region and mostly threatened by erosion were chosen for the experiment, i.e. a traditional vineyard, an espalier vineyard and a young orchard plantation. $2 \times 2$ erosion plots (one partly covered by geotextiles and one uncovered plot with a repetition of each), with an extent of $2 \times 10 \mathrm{~m}$ were established on a slope of $19.44 \%$ with western slope aspect. On the covered plots the lower $50 \%$ of the soil surface was covered by jute mats. The soil type is luvisol (silty loam), the soil parent material is amphibole andesite.

Important characteristics of the climate are as follows. The average precipitation amount is $597 \mathrm{~mm} /$ year, the maximum rainfall intensity is $83 \mathrm{~mm} / \mathrm{h}$ ( $1 \%$ probability) and the potential evaporation is $750 \mathrm{~mm} /$ year.

Runoff and sediment measurements and collection are carried out by a system developed by the Hungarian team. At the lower end of the plots two runoff collectors are installed and connected by a 1:9 divisor. The upper tank (60 1 capacity) captures $100 \%$ of the eroded sediment. If the amount of runoff is more then 601 , the surplus will flow towards the next tank of 2001 capacity. 
The divisor between the two tanks will lead away $90 \%$ of the runoff water, so that $10 \%$ of the amount over 601 will be collected in the second, bigger collector tank.

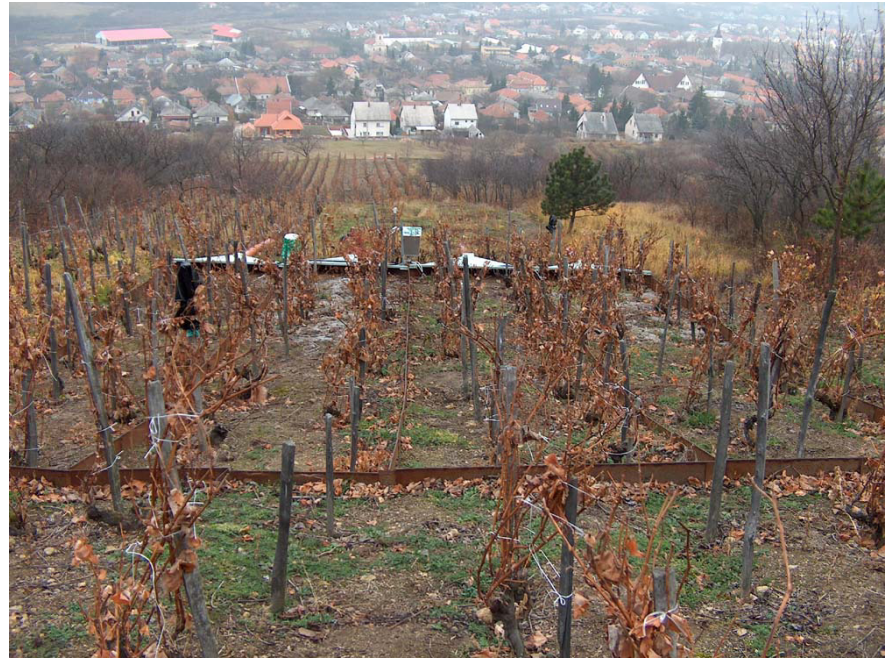

Figure 1: $\quad$ Traditional vineyard plots.

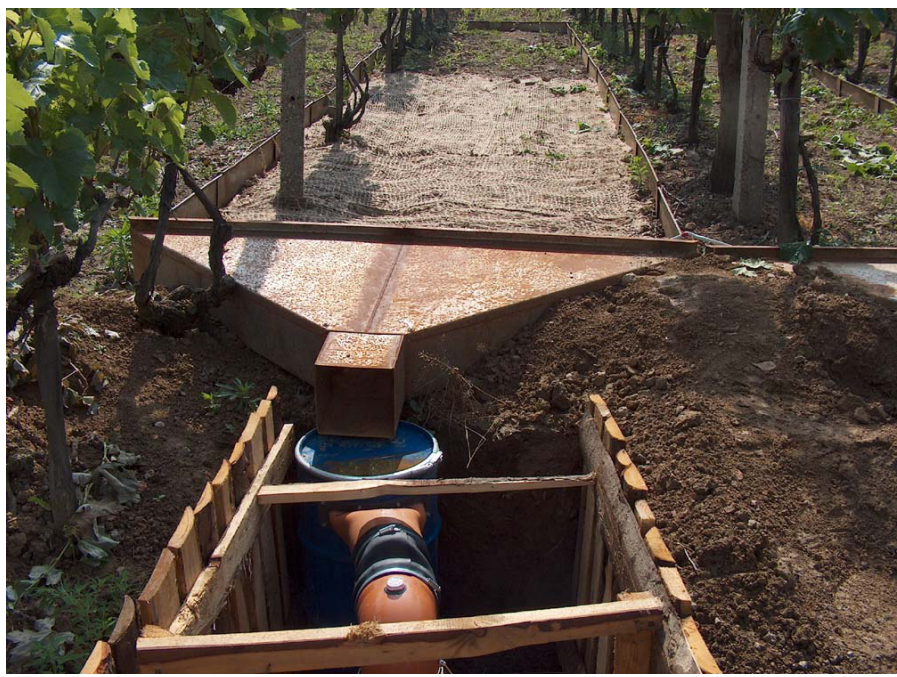

Figure 2: $\quad$ Covered runoff plot in espalier vineyard.

\section{Results}

Runoff measurements have been going on since June 2006 whereas the eroded sediment has been collected since August 2006. 
It is important to note that particle size compositions of the soils of the plots representing three different land use types are different. In the espalier vineyard and in the orchard the proportion of skeleton $(<2 \mathrm{~mm})$ is $5 \%$ less than in the conventional vineyard. The proportion of the clay fraction is roughly $1 \%$ more, that of silt is $3.5 \%$ and sand is $0.6 \%$ more on the plots of traditional vineyard, compared to the other two land use types (Figure 3).

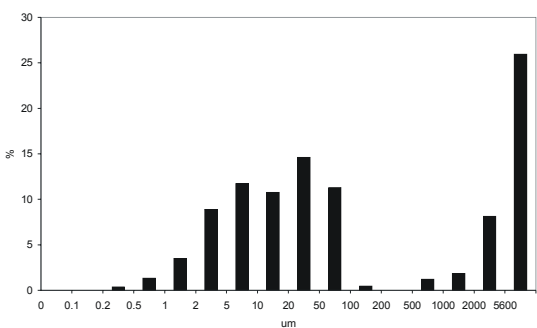

Traditional vineyard

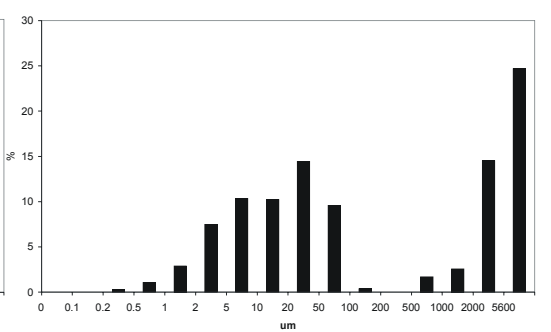

Espalier vineyard and orchard

Figure 3: $\quad$ Soil texture diagram of the plots.

Altogether 35 rainfall events were recorded in 2006 (Table 1). From the point of view of the amount of soil loss two critical precipitation values (rainfall events) could be identified: a $5.4 \mathrm{~mm}$ and a $29.4 \mathrm{~mm}$ rainfall event. The former is the threshold value to get soil loss and the latter refers to a jump in the amount of soil loss on the espalier vineyard (see Table 1).

The threshold precipitation value of runoff initiation was $5.4 \mathrm{~mm}$, irrespectively of the use of geotextiles and of land use type (Table 3).

Table 1: $\quad$ Rainfall events (June - December 2006).

\begin{tabular}{|c|c|c|c|c|c|}
\hline \multicolumn{2}{|c|}{$0.1-1.0 \mathrm{~mm} /$ event } & \multicolumn{2}{c|}{$1.1-10.0 \mathrm{~mm} /$ event } & \multicolumn{2}{c|}{$<10.0 \mathrm{~mm} /$ event } \\
\hline 01.06 .2006 & 0.8 & 05.06 .2006 & 6.8 & 02.06 .2006 & 13 \\
\hline 14.06 .2006 & 0.4 & 09.06 .2006 & 1 & 03.06 .2006 & 23.2 \\
\hline 01.07 .2006 & 0.6 & 20.06 .2006 & 2 & 04.06 .2006 & 11.4 \\
\hline 15.07 .2006 & 0.2 & 22.06 .2006 & 8.4 & 23.06 .2006 & 20.2 \\
\hline 22.07 .2006 & 0.6 & 29.06 .2006 & 4.8 & 27.06 .2006 & 22.8 \\
\hline 15.10 .2006 & 0.2 & 30.06 .2006 & 5.6 & 03.08 .2006 & 10.1 \\
\hline 26.10 .2006 & 0.2 & 29.07 .2006 & 5.4 & 10.08 .2006 & 23.8 \\
\hline 01.11 .2006 & 0.6 & 30.07 .2006 & 1.4 & 12.08 .2006 & 29.4 \\
\hline 02.11 .2006 & 0.2 & 22.10 .2006 & 4.2 & 01.09 .2006 & 25.1 \\
\hline 05.11 .2006 & 0.6 & 24.10 .2006 & 4.6 & & \\
\hline 07.11 .2006 & 0.2 & 29.10 .2006 & 4.2 & & \\
\hline 09.11 .2006 & 0.2 & 29.10 .2006 & 4.2 & & \\
\hline 10.11 .2006 & 0.2 & 13.11 .2006 & 1.6 & & \\
\hline 12.11 .2006 & 0.2 & 12.12 .2006 & 9.3 & & \\
\hline
\end{tabular}

Total: 35 events.

A new rainfall event starts when at least 6 hours passed since the last event. 
Table 2: $\quad$ Sediment yield $\left(\mathrm{g} / \mathrm{m}^{2}\right)$.

\begin{tabular}{|c|c|c|c|c|c|c|}
\hline \multirow{2}{*}{$\begin{array}{c}\text { Pre- } \\
\text { cipitation } \\
(\mathrm{mm})\end{array}$} & \multicolumn{6}{|c|}{ Sediment yield $\left(\mathrm{g} / \mathrm{m}^{2}\right)$} \\
\cline { 2 - 7 } & \multicolumn{2}{|c|}{ Espalier vineyard } & \multicolumn{2}{c|}{ Traditional vineyard } & \multicolumn{2}{c|}{ Orchard } \\
\cline { 2 - 7 } & covered & uncovered & covered & uncovered & covered & uncovered \\
\hline 5.4 & 0.60 & 0.95 & 0.23 & 0.25 & 0.47 & 1.90 \\
\hline 5.6 & 0.63 & 0.73 & 0.18 & 0.20 & 0.95 & 0.31 \\
\hline 6.8 & 0.68 & 0.73 & 0.19 & 0.23 & 0.39 & 0.65 \\
\hline 25.1 & 0.60 & 0.85 & 0.18 & 0.15 & 0.30 & 0.63 \\
\hline 29.4 & 1.63 & 21.98 & 0.15 & 0.20 & 0.22 & 0.12 \\
\hline
\end{tabular}

Table 3: $\quad$ Runoff amount (mm).

\begin{tabular}{|c|c|c|c|c|c|c|}
\hline \multirow{2}{*}{$\begin{array}{c}\text { Pre- } \\
\text { cipitation } \\
(\mathrm{mm})\end{array}$} & \multicolumn{7}{|c|}{ Runoff $(\mathrm{mm})$} \\
\cline { 2 - 7 } & \multicolumn{2}{|c|}{ Espalier vineyard } & \multicolumn{2}{c|}{ Traditional vineyard } & \multicolumn{2}{c|}{ Orchard } \\
\cline { 2 - 7 } & covered & uncovered & covered & uncovered & covered & uncovered \\
\hline 6.8 & 0.03 & 0.10 & 0.01 & 0.01 & 0.03 & 0.10 \\
\hline 5.4 & 0.06 & 0.04 & 0.02 & 0.01 & 0.05 & 0.02 \\
\hline 5.6 & 0.06 & 0.04 & 0.02 & 0.01 & 0.05 & 0.03 \\
\hline 9.3 & 0.14 & 0.06 & 0.06 & 0.01 & 0.25 & 0.07 \\
\hline 23.8 & 0.12 & 0.24 & 0.04 & 0.04 & 0.08 & 0.16 \\
\hline 25.1 & 4.53 & 4.48 & 1.63 & 0.88 & 2.63 & 2.15 \\
\hline 29.4 & 0.18 & 0.28 & 0.06 & 0.05 & 0.13 & 0.19 \\
\hline
\end{tabular}

Table 4: $\quad$ Runoff coefficient (\%).

\begin{tabular}{|c|c|c|c|c|c|c|}
\hline \multirow{2}{*}{$\begin{array}{c}\text { Pre- } \\
\text { cipitation } \\
(\mathrm{mm})\end{array}$} & \multicolumn{6}{|c|}{ Runoff $(\%)$} \\
\cline { 2 - 7 } & \multicolumn{2}{|c|}{ Espalier vineyard } & \multicolumn{2}{c|}{ Traditional vineyard } & \multicolumn{2}{c|}{ Orchard } \\
\cline { 2 - 7 } & covered & uncovered & covered & uncovered & covered & uncovered \\
\hline 5.4 & 0.63 & 1.79 & 0.21 & 0.13 & 0.47 & 1.90 \\
\hline 5.6 & 1.06 & 0.79 & 0.33 & 0.21 & 0.95 & 0.31 \\
\hline 6.8 & 0.50 & 1.42 & 0.17 & 0.10 & 0.37 & 1.51 \\
\hline 9.3 & 1.50 & 0.60 & 0.65 & 0.07 & 2.71 & 0.75 \\
\hline 25.1 & 0.46 & 0.94 & 0.16 & 0.16 & 0.30 & 0.63 \\
\hline 29.4 & 0.25 & 0.19 & 0.06 & 0.04 & 0.22 & 0.12 \\
\hline
\end{tabular}

Runoff amount (Table 3) and runoff rate (Table 4) were not effected by land use. Runoff values in the espalier vineyard characterized by the largest specific leaf area were similar to those in the newly planted orchard with a minimum leaf area value. Higher runoff values on the espalier and orchard plots can probably be explained by higher skeleton content values of their upper soil layers.

In most cases runoff volume was more on the plots (partly) covered by geotextiles (see Tables 3 and 4). Before the middle of June runoff volume was larger on the uncovered espalier vineyard and orchard plots. A possible explanation for this is the fact that geotextiles were placed on the plots early June and being totally dry at that time they could take up much more water than later. 
After the system has reached a steady state geotextiles lead to an increase of runoff in spite of the fact that they provide higher surface roughness and that they can take up a considerable amount of rainfall water. In case of the $29.4 \mathrm{~mm}$ rainfall event the amount of runoff was larger on the uncovered espalier plot and on the orchard plot and just slightly less on the traditional vineyard plot. This measurement result suggests that above a threshold value of rainfall amount geotextiles have a positive effect on runoff amount.

The role of geotextiles proved to be important in equalising soil moisture conditions, i.e. the topsoil dries out much slower if covered by geotextiles. This positive effect could be detected also at a depth of $20 \mathrm{~cm}$ (see Figure 4). Table 5 contains durations of soil saturation, durations of soil desiccation are shown in Table 6. Geotextiles slow down the saturation process of the soil surface on one hand and they slow down the desiccation process after the rainfall event on the other.
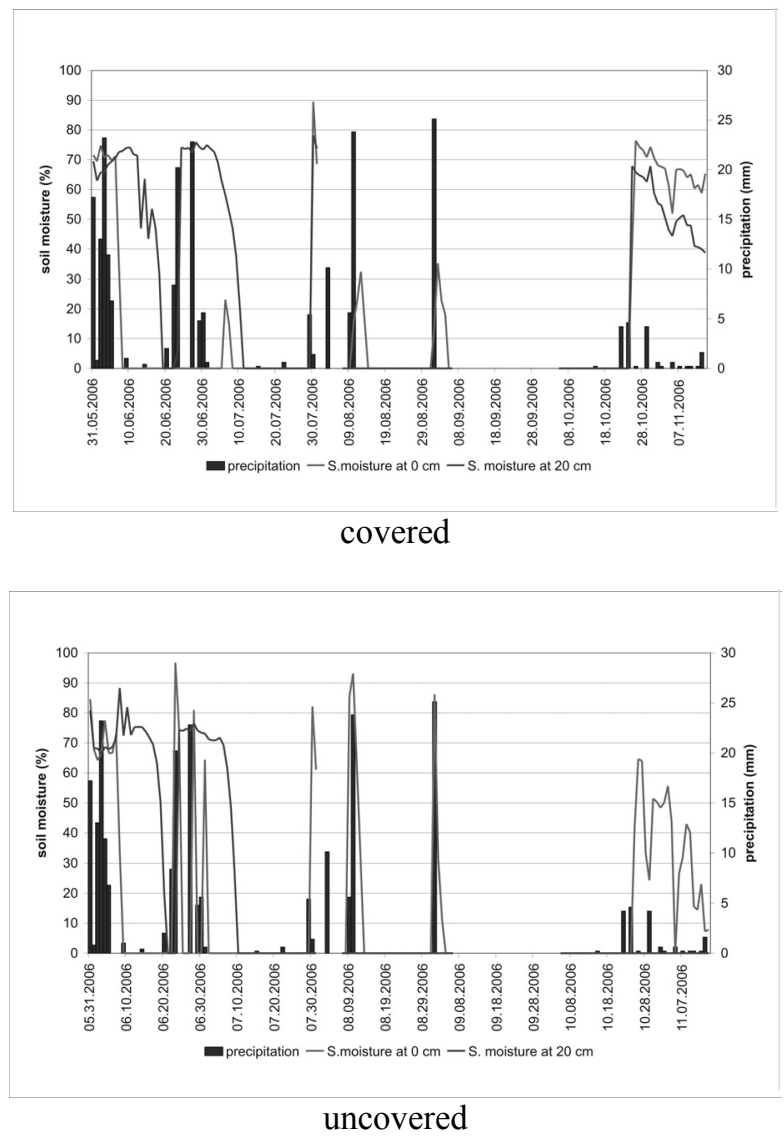

Figure 4: Precipitation amount $(\mathrm{mm})$ and soil moisture percentage $(\%)$ on soils covered by geotextiles and on uncovered soils. 
Table 5: $\quad$ Time needed to reach soil saturation.

\begin{tabular}{|l|c|c|}
\hline & covered & uncovered \\
\hline soil surface & 23 hours & 4 hours \\
\hline $20 \mathrm{~cm}$ below surface & 97 hours & 23 hours \\
\hline
\end{tabular}

Table 6: $\quad$ Time needed for desiccation ${ }^{*}$ of saturated soil.

\begin{tabular}{|l|c|c|}
\hline & covered & uncovered \\
\hline soil surface & 196 hours & 98 \\
\hline $20 \mathrm{~cm}$ below surface & 392 hours & 315 \\
\hline
\end{tabular}

*desiccation means reaching permanent wilting point.

The threshold precipitation value leading to soil loss is $5.4 \mathrm{~mm}$, as mentioned above. No affect of rainfall intensity on soil loss could be proved up to now. In the range of $5.4-29.4 \mathrm{~mm}$ the amount of soil loss was always less than 0.01 $\mathrm{t} / \mathrm{ha}\left(1 \mathrm{~g} / \mathrm{m}^{2}\right)$.

Soil loss values are different under different land uses (see Table 2). Soil loss values on the espalier plot are the highest, followed by orchard and traditional vineyard. An explanation for this is difficult to find. Differing compaction of the soil surface can be a reason for this, i.e. compaction is the highest on the espalier vineyard caused by machinery.

In most cases soil loss is higher on the uncovered plots. The difference is 8$50 \%$. The biggest difference is on the orchard plots and the smallest is on the traditional vineyard.

On the espalier plot the amount of soil loss caused by the biggest rainfall event of $29.4 \mathrm{~mm}$ is one order bigger on the covered plots and two orders bigger on the uncovered plot, compared to soil loss values measured at smaller rainfall events. The difference is not that big in case of the other land use types.

The modus value of the soil texture falls in the $20-50 \mu \mathrm{m}$ interval and the same is true for the eroded soils. It is important to note that both the finer and the coarser fractions are underrepresented in the eroded soils.

Concerning the texture of the eroded soil the following differences could be detected between the three land use types.

- $\quad$ Orchard - similar grain size compositions belong to the soil losses produced at different rainfall amounts and intensities. There was no difference between the covered and the uncovered plots (see Figure 5).

- $\quad$ Espalier vineyard - similar to the orchard but bigger rainfall events lead to the erosion of a larger quantity of coarser particles $(>50$ $\mu \mathrm{m})$ on the uncovered plot. This phenomenon could not be observed on the covered plot.

- $\quad$ Traditional vineyard - here the proportion of coarser soil particles is on the covered plot bigger and not on the uncovered plot when bigger rainfall events happen. 


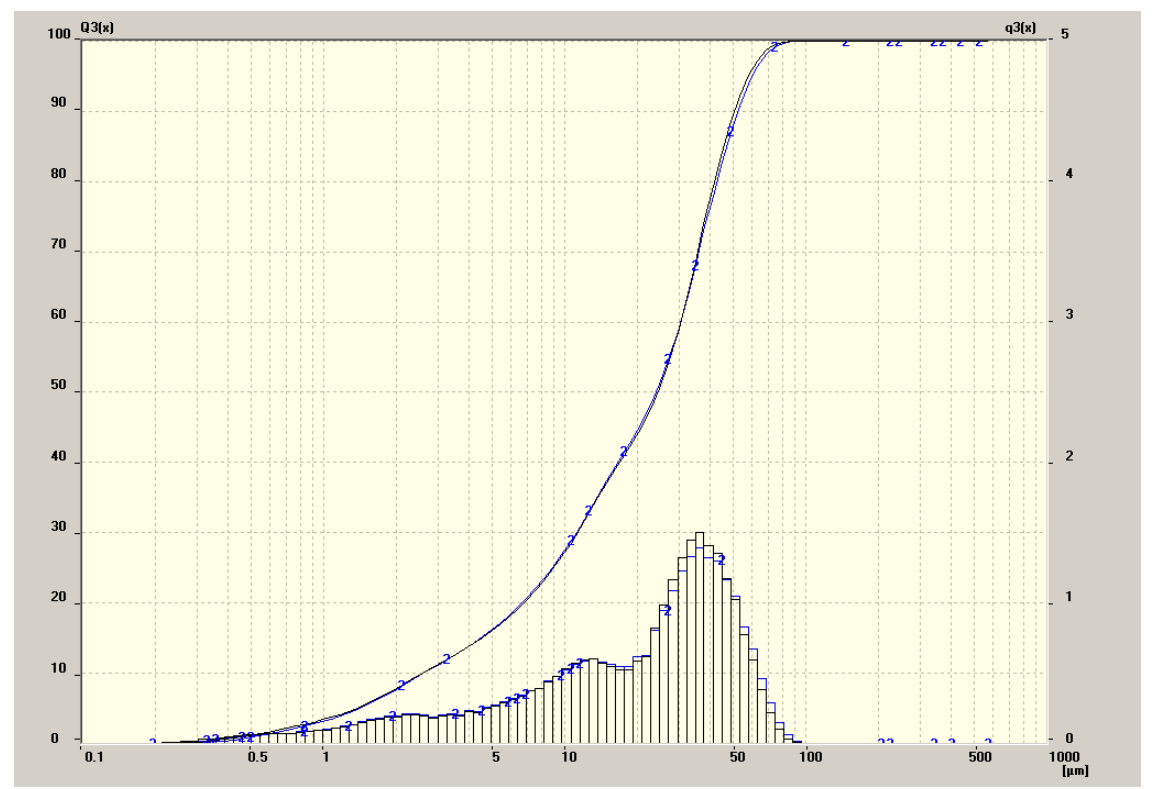

Figure 5: Grain size distribution of the soil eroded from the covered and uncovered orchard plots (10.8.2006, $29.4 \mathrm{~mm}$ rainfall). The curves run so close to each other that they can hardly be distinguished.

\section{Conclusions}

(1) The protecting effect of geotextiles could be detected at each rainfall event leading to soil loss.

(2) The texture of the eroded soil was not affected by the geotextile cover.

(3) Runoff volume was increased on plots under geotextile cover.

(4) The effect of different land uses influenced first of all the amount of soil loss.

(5) There was no relationship between land use and runoff volume.

(6) Our preliminary results show that the most important role of the application of geotextiles is in providing favourable soil moisture conditions and as a consequence of this a favourable soil micro climate.

\section{References}

[1] Booth, C.A., Davies, K. \& Fullen, M.A., Environmental and socioeconomic contributions of palm-leaf geotextiles to sustainable development and soil conservation. Ecosystems and sustainable development V., WIT Transactions on Ecology and the Environment, Vol 81., ed. E. Tiezzi, C.A. Brebbia, S.E. Jorgensen \& D. Almorza Gomar, WIT Press: Southampton, pp. 649-658., 2005. 
[2] Gumaa, Y.T., Haffar, I. \& Al-Afifi, M.A., Financial appraisal of datefrond mat fence systems for wind erosion control and dune stabilisation in the arid regions of the United Arab Emirates. Journal of Arid Environments, 39, pp. 549-557, 1998.

[3] Sutherland, R.A. \& Ziegler, A.D., Geotextile effectiveness in reducing interrill runoff and sediment flux, In: International Erosion Control Association Proceedings of Conference XXVI, 1995, Atlanta, (USA), pp. 359-370, 1996.

[4] Ogbobe, O., Essien, K.S. \& Adebayo, A., A study of biodegradable geotextiles used for erosion control. Geosynthetics International, 5, pp. 545-553, 1998. 